\title{
Incidence trends in childhood onset IDDM in four countries around the Baltic sea during 1983-1992
}

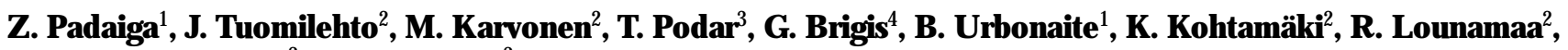 \\ E. Tuomilehto-Wolf ${ }^{2}$, A . R eunanen ${ }^{2}$ \\ ${ }^{1}$ Institute of E ndocrinology, K aunas M edical A cademy, Lithuania \\ ${ }^{2} \mathrm{~N}$ ational Public H ealth Institute, D epartment of $\mathrm{E}$ pidemiology and $\mathrm{H}$ ealth Promotion, $\mathrm{D}$ iabetes and $\mathrm{G}$ enetic $\mathrm{E}$ pidemiology $\mathrm{U}$ nit, \\ $\mathrm{H}$ elsinki, Finland \\ ${ }^{3} \mathrm{H}$ ospital of E ndocrinology, D epartment of Internal M edicine, U niversity of Tartu, Tartu, E stonia \\ ${ }^{4} \mathrm{D}$ epartment of Public H ealth and E pidemiology, L atvian M edical A cademy, R iga, L atvia
}

Summary We present secular trends of childhood onset insulin-dependent diabetes mellitus (IDDM) in Finland, E stonia, L atvia and L ithuania during the period of 1983-1992. Incidence data were obtained from the national ID D M registries. The average agestandardized incidence per 100000/year was 35.0 in Finland, followed by 10.2 in E stonia, 7.1 in L ithuania and 6.5 in L atvia. A male excess in incidence was recorded in Finland (1.15) and Latvia (1.01). In all countries, the highest age-specific risk of IDDM was observed in the 11-13 year age range. The large difference in incidence between Finland and other B altic countries was seen even in 1-2-year-old children. D uring the 10-year study period overall changes in incidence of IDDM were relatively small in these four countries. The incidence increased in Finland and
Lithuania on average by $1 \%$ and $1.4 \%$ per year, respectively. A statistically significant increase was recorded only in 0-4 year old children in Finland, at $5.6 \%$ per year. In Estonia, an $8.3 \%$ increase in this age group, however, was not statistically significant. The different trends in the age-group specific incidence rates were confirmed in Finland. I conclusion, from 1983 to 1992 the incidence of childhood onset IDDM was increasing in Finland and Lithuania, while in Latvia and $E$ stonia it was stable. There are still great differences in IDDM incidence between the countries around the Baltic Sea. [D iabetologia (1997) 40: 187-192]

Keywords Insulin-dependent diabetes mellitus, incidence, secular trends.
Incidence of childhood insulin-dependent diabetes mellitus (IDD M ) is rising in many areas of the world $[1,2]$. D espite the role of $H L A$ genetics in the aetiology of ID DM being well known $[3,4]$ the role of putative environmental factors is not yet understood [5-7]. E pidemiologically based standardized surveillance systems provide information on the pattern of IDDM incidence which make comparison of IDDM incidence between countries within close geographical areas possible, thus offering an "indirect" way to trace potential environmental factors in the aetiology

R eceived: 27 M ay 1996 and in revised form: 4 September 1996

Corresponding author: Professor J. Tuomilehto, N ational Public $\mathrm{H}$ ealth Institute, D iabetes R esearch Centre, D epartment of Epidemiology and $\mathrm{Health}$ Promotion, $\mathrm{M}$ annerheimintie 166, FIN-00300 H elsinki, Finland

A bbreviations: ID D M, Insulin-dependent diabetes mellitus. of IDDM. A collaborative study on the childhood IDDM incidence in countries around the Baltic Sea was started in 1989 named "D I A B A LT". Short-term data have demonstrated a wide variation in the incidence of IDDM between countries around the Baltic Sea $[8,9]$, from the highest incidence in the world in Finland to one of the lowest within E urope in Poland. In order to obtain more standardized rates for comparison of secular trends in incidence of IDDM in Finland, E stonia, L atvia and Lithuania the analyses of the data were carried out for the period 1983 to 1992.

\section{Subjects and methods}

G eographically the B altic States of E stonia, L atvia and Lithuania are located on the south-east coast, while Finland is on the northern coast of the B altic Sea. G enetically and culturally, the population of Finland is homogeneous [10], while E stonia 
and Latvia have a considerable admixture of immigrant groups, mainly R ussian in origin. In 1989, $61 \%$ of the $E$ stonian population were Estonian and $30 \%$, R ussian [11]. Other ethnic groups in E stonia consisted of $U$ krainians (3\%), B yelorussians ( $1 \%$ ), J ews, Polish and L atvians. I $\mathrm{L}$ atvia the proportion of native L atvians was $52 \%$, while R ussians constituted $34 \%$ [12]. The rest of the population consisted of $4.5 \%$ Byelorussians, 3.5\% U krainians, Polish and Lithuanians. The admixture of $\mathrm{R}$ ussian population in Lithuania was less than $10 \%$ in 1989 [13], and is still decreasing. O ther ethnic groups were Polish (7\%), Byelorussians ( $2 \%)$, U krainians, Jews, Latvians and Germans.

The following standard case-definition criteria for childhood IDDM were used in all countries: 1) diagnosed as diabetic patient; 2) placed on insulin therapy before the 15th birthday; 3 ) resident of the country at the time of the first insulin administration.

\section{Case ascertainment}

Finland. The Central D rug R egister of the Social Insurance Institution was used for the period 1983 to 1986. Since 1987, data from a prospective nationwide register for childhood diabetes were used. H ospital records of incident cases were used as the main data source (all newly diagnosed diabetic children are hospitalized for 1-2 weeks). D ata from the Social Insurance Institution served as an independent data source for case ascertainment [14].

Estonia. The childhood diabetes register was compiled retrospectively in 1988-1989, starting from 1989 it has been done prospectively. R eports from district paediatricians were used as the main data source. Medical records from the Republic Endocrinology Center served as an independent source for case ascertainment $[8,9]$.

L ithuania. D ata were collected prospectively using annual reports from regional paediatricians and endocrinologists. A s a secondary data source (however not fully independent), annual statistics from the Ministry of $\mathrm{H}$ ealth were used. Since 1989, medical records of in-patient childhood endocrinology departments (which were established in 1989 and where all newly diagnosed diabetic children are hospitalized) were used as the main data source. A nnual reports from regional paediatricians and endocrinologists remained as an independent source for case ascertainment $[9,15]$.

$L$ atvia. D ata were obtained from the prospective childhood diabetes register. M edical records from the department of endocrinology of the Children's Hospital were used as the main data source. A nnual reports from regional paediatricians were used as an independent data source for case ascertainment [9].

Currently, all countries continue the prospective collection of incidence data within the framework of the World $\mathrm{H}$ ealth O rganization (WHO) DIAMOND Project [16]. The degree of case-ascertainment was estimated according to the capturerecapture method [17]. A scertainment ranged from 95 to $100 \%$ in all the countries except $L$ atvia where it was between 80 and $100 \%$.

\section{Statistical analysis}

The average annual incidence rates were calculated per 100 000 population per year. The mid-year populations aged 14 years and under were used as the denominator. The $95 \%$ confidence interval was estimated assuming the Poisson
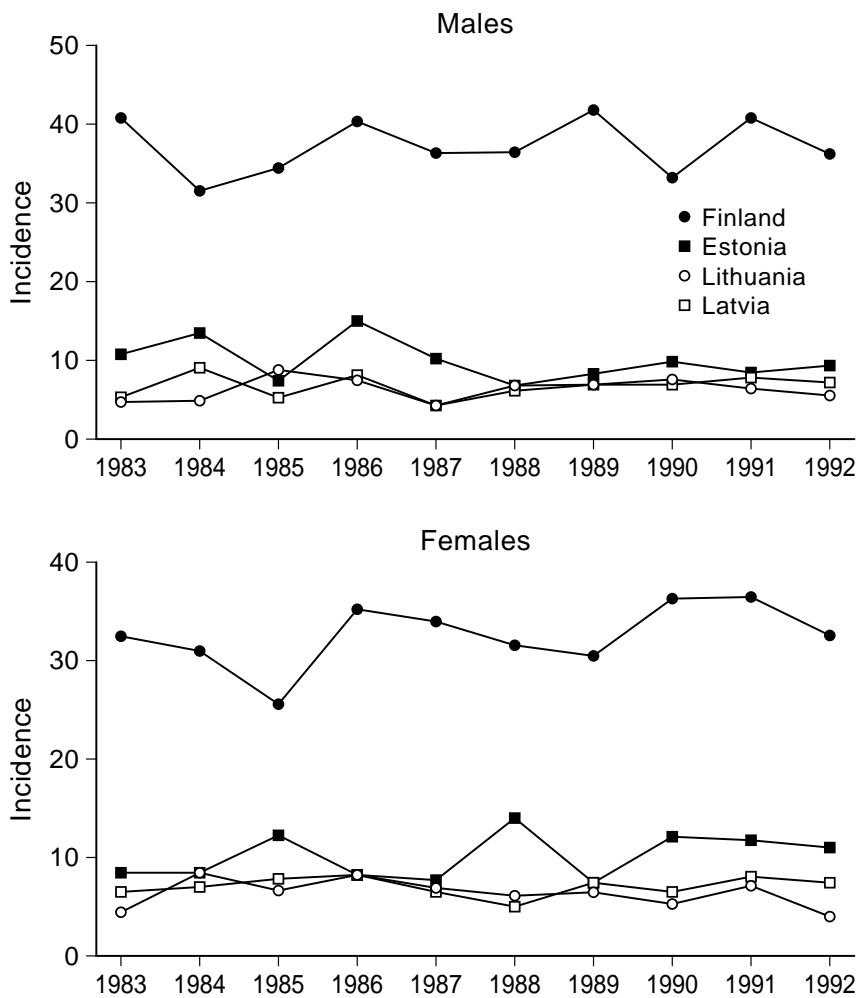

Fig. 1. A ge-standardized incidence of IDDM in children aged 14 years or under in countries (Finland, Estonia, L atvia and Lithuania) around the B altic Sea, 1983 to 1992

distribution of the cases. A ge adjustment of the rates was done using 5-year intervals (0-4, 5-9 and 10-14 years) with the proportions $1 / 3,1 / 3$ and $1 / 3$, respectively as the standard according to the previous approach by the Diabetes $E$ pidemiology R esearch International Study G roup [18].

The change in IDDM incidence from 1983 to 1992 was estimated by fitting the linear regression with the annual incidence data. The change per unit in regression coefficient (regression slope) demonstrates the absolute change in incidence per year. The secular trend in IDDM incidence (relative change) was also calculated from logarithms of incidence using linear regression, where the regression coefficient is approximately the change per year as a percentage unit. The differences in incidence between the sexes, difference between the three age groups (0-4, 5-9, 10-14 years) and between two periods (1983-1985, 1990-1992) were tested with A NOVA procedure.

\section{Results}

The age-standardized incidence of IDDM in four populations during the 10-year study period is presented in Figure 1. The highest incidence (35 per $100000 /$ year) was found in Finland whereas in E stonia, Latvia and Lithuania the incidence was markedly lower (Table 1). The age distribution of ID D M incidence presented in Figure 2 showed that in all countries, the highest age-specific risk of IDDM was observed around $11-13$ years of age. In males the highest ID D M incidence was recorded in the 10-14 year 
Table 1. Incidence of ID D M (per 100000/year) in children aged 14 years or under in four countries around the Baltic Sea from 1983 to 1992

\begin{tabular}{|c|c|c|c|c|c|c|c|c|c|c|}
\hline \multirow[t]{3}{*}{ Country } & \multicolumn{4}{|c|}{ Males } & \multicolumn{4}{|c|}{ Females } & \multicolumn{2}{|l|}{ AII } \\
\hline & \multicolumn{4}{|c|}{ A ge (years) } & \multicolumn{4}{|c|}{ A ge (years) } & \multirow[b]{2}{*}{ Alla } & \multirow[b]{2}{*}{$\begin{array}{l}\text { M ale/female } \\
\text { ratio }^{b}\end{array}$} \\
\hline & $0-4$ & $5-9$ & $10-14$ & A lla & $0-4$ & $5-9$ & $10-14$ & A $\|^{a}$ & & \\
\hline Finland & 25.5 & 40.4 & 46.3 & $37.4(35.7 ; 39.1)$ & 23.3 & 37.9 & 36.6 & $32.6(31.0 ; 34.3)$ & $35.0(33.9 ; 36.2)$ & 1.15 \\
\hline E stonia & 4.3 & 9.7 & 16.5 & $10.2(8.7 ; 11.8)$ & 5.0 & 11.9 & 14.0 & $10.3(8.8 ; 12.0)$ & $10.2(9.2 ; 11.4)$ & 0.99 \\
\hline Lithuania & 4.4 & 7.5 & 9.0 & $7.0(6.2 ; 7.8)$ & 3.3 & 8.7 & 9.8 & $7.2(6.4 ; 8.1)$ & $7.1(6.5 ; 7.7)$ & 0.97 \\
\hline Latvia & 3.3 & 5.5 & 11.0 & $6.6(5.7 ; 7.6)$ & 3.4 & 6.7 & 9.3 & $6.5(5.6 ; 7.5)$ & $6.5(5.9 ; 7.2)$ & 1.01 \\
\hline
\end{tabular}

${ }^{a}$ A ge-standardized incidence and $95 \%$ confidence intervals for children aged 14 years or under; ${ }^{b}$ male to female ratio in age-standardized incidence

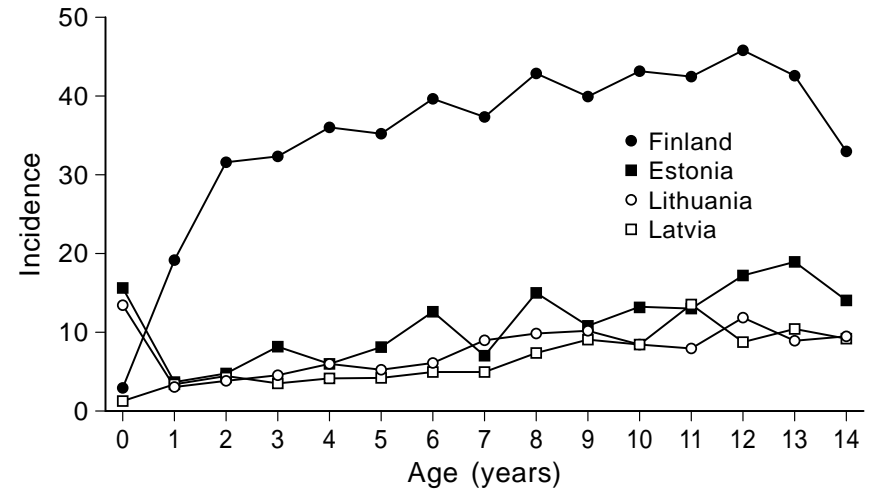

Fig. 2. A ge distribution of IDDM incidence in children aged 14 years or under in countries (Finland, E stonia, Latvia and L ithuania) around the B altic Sea 1983 to 1992

age group in all populations. Similar patterns existed for females in all countries except Finland, where the highest incidence was in 5-9-year-olds. The large difference in incidence between Finland and the three Baltic republics of Estonia, Latvia and Lithuania was seen also among 1-2-year-old children. A male excess in incidence was recorded in Finland (1.15), whereas in other countries no clear difference in incidence between sexes was seen.

Regression-based linear trends in IDDM incidence during 1983-1992 for each country is shown in Figure 3. R esults of the regression models (Table 2) showed an increasing incidence of IDDM in Finland and $L$ ithuania. The average increase in incidence, estimated from the regression coefficients, was 0.32 and 0.09 per 100000/year, respectively, and the increase in incidence per year during 1983-1992 was $1 \%$ in Finland and $1.4 \%$ in Lithuania, but these slopes did not reach statistical significance. There was no change in the incidence in $E$ stonia and $L$ atvia.

The age-group specific analyses showed a statistically significant increase in IDD M incidence in 0-4year-olds in Finland ( $p<0.005$, Table 2$)$, but not in children aged $5-14$ years. On the contrary, the incidence in Lithuania increased in 5-14-year-olds. In E stonia, ID D M incidence slightly increased in 0-4-yearolds with a regression slope of 0.4 and $8.3 \%$ change in incidence per year. However, due to the relatively small number of cases the results should be interpreted with caution.

A nalysis of variance showed a significant agegroup variation in incidence in all countries $(p=0.0001)$. O nly in Finland was the incidence significantly higher in males than in females $(p=0.004)$. When comparing the first 3 years (1983-1985) with the last 3 years (1990-1992) of the study period, a significant variation was observed in Finland $(p=0.047)$. The statistically significant interaction between period and age group in Finland $(p=0.015)$ confirmed the observation of different incidence trends among the three age groups. When separately analysing the $0-4$ and 5-14-year-age groups, the period effect $(p=0.005)$ and the interaction between the age group and period in Finland became more pronounced $(p=0.005)$. In Finland, the incidence rate ratio between 10-14-year-olds and 0-4-year-olds changed from 2.1 during 1983-1985 to 1.4 during 1990-1992.

\section{Discussion}

The variation in IDDM incidence among the countries around the Baltic Sea during 1983 to 1992 remained almost the same as reported earlier in the 1980s [9]. The incidence in Finland was 3-5 times higher than in the B altic republics of E stonia, Latvia and $L$ ithuania. The reason for such a large difference in incidence within relatively small geographic area is unknown. O ne theory is that the pool of individuals genetically susceptible to ID D M has been increasing more in some countries than in others [19]. This may be partly associated with different survival rates of young onset IDDM patients. Data from Estonia show a lower survival of childhood onset ID D M patients compared with Finland.

In Finland and in many other industrialized countries, perinatal mortality rates for diabetic pregnancies have decreased since the 1970s and now they are approaching those of the general population [20, 21]. R esults from the Joslin D iabetes Center, B oston, 


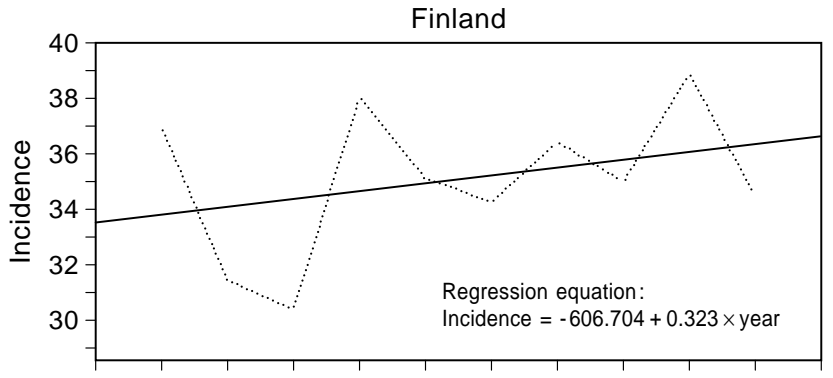

198219831984198519861987198819891990199119921993

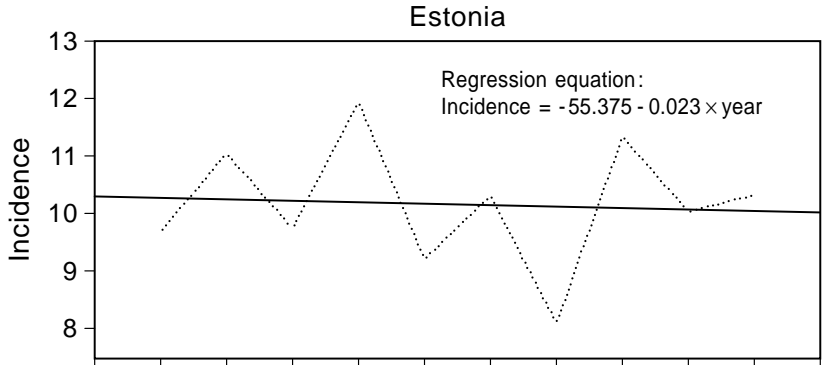

198219831984198519861987198819891990199119921993

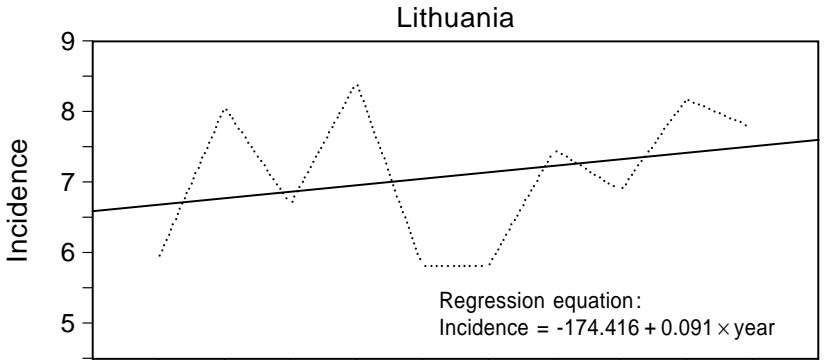

198219831984198519861987198819891990199119921993

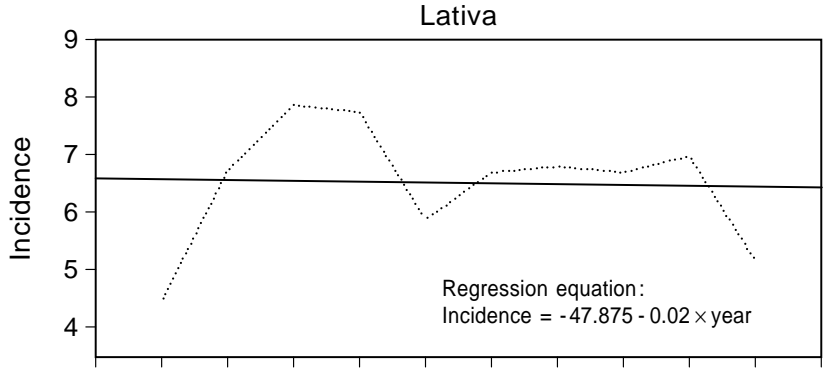

198219831984198519861987198819891990199119921993

Fig. 3. Trends in IDDM incidence in children aged 14 years or under in countries (Finland, Estonia, L atvia and Lithuania) around the Baltic Sea 1983 to 1992

M ass., U SA show that perinatal mortality of diabetic pregnancies was $23 \%$ before 1961 . A fter a dramatic drop in 1961 it stabilized around 14\% until 1975, and since then it has decreased to $4 \%$ [22]. It has been shown that half of the fetal deaths occur due to poor metabolic control of mothers with IDDM or gestational diabetes, $\mathrm{HbA}_{1 \mathrm{c}}$ (assessed by chromatographic methods with ranges of $5-8 \%$ representing healthy metabolism) also has a significant and independent effect on severe neonatal morbidity [23, 24]. The review of existing data on the determinants of perinatal outcome in diabetic pregnancies concluded that metabolic control during gestation is more important than duration of diabetes [25]. M aternal mortality of diabetic pregnancies followed the same pattern as perinatal mortality $[20,21,24,26]$.

$M$ arked differences in specific health indicators exist between Finland and the B altic republics. Perinatal mortality in E stonia, L atvia and L ithuania - 16.0; $18.7 ; 15.6$ per 1000 births, respectively [27] - is extremely high compared with 4.4 in Finland [28]. A Iso, overall maternal mortality rates differ greatly, with an average rate of 31 per 100000 live births in the $B$ altic republics compared to 4.7 in Finland [29]. No comparable data on perinatal and maternal mortality rates in diabetic pregnancies exist in E stonia, Latvia and Lithuania. However, higher mortality rates in the general population, as well as overall deterioration in the public health situation over the last few years, cannot suggest selective stabilization or even improvement in health of diabetic patients. A Ithough we do not have data for comparison of metabolic control between countries, the recent findings from $\mathrm{L}$ ithuania show that the mean $\mathrm{HbA}_{1}$ of diabetic children was 12-14\% during 1992-1994 [30], which is extremely high compared with internationally accepted levels of metabolic control, which according to Diabetes Control and Complications trial (DCCT) criteria should be less than 8.4\% [31].

The reasons for the high and increasing IDDM incidence in Finland are unknown and can only be speculated. It is possible that a pool of genetically susceptible individuals has increased in Finland during the past decades more rapidly than in Estonia, $L$ atvia and Lithuania; although at present we do not have sufficient data, this possibility cannot be excluded.

The incidence of IDDM varies markedly within E urope, even within relatively small areas. In the former eastern E uropean countries incidence is lower than that on average in the rest of E urope. H owever, there seems to be marked similarity in incidence among these countries, despite the wide variation both in their genetic background and physical environment, due to the great geographical distance (about $3300 \mathrm{~km}$ ) in south-north direction between countries. The identical socio-economic systems and uniform health care systems associated with poor control of IDDM, high morbidity and mortality in IDDM and high infant mortality suggest that these factors may have prevented the increase in the genetic pool predisposing to IDDM .

In E stonia, non-E stonians have a significantly lower risk of IDDM compared to native Estonians [11]. It is very likely that similar differences in ID D M risk exist in $L$ atvia. Thus, part of the incidence variability between the $B$ altic republics may be due to ethnic differences. Simultaneously, non-E stonians (mainly R ussians) living in E stonia had significantly higher risk of IDDM compared to the population of 
Table 2. R egression slopes and the regression-based change in ID DM incidence in children aged 14 years or under in four countries around the Baltic Sea from 1983 to 1992

\begin{tabular}{|c|c|c|c|c|c|c|c|c|c|c|}
\hline \multirow[t]{3}{*}{ Country } & \multicolumn{6}{|l|}{ A ge group } & \multirow{2}{*}{\multicolumn{2}{|c|}{ M ales }} & \multirow{2}{*}{\multicolumn{2}{|c|}{ Females }} \\
\hline & \multicolumn{2}{|l|}{$0-4$ years } & \multicolumn{2}{|l|}{$5-9$ years } & \multicolumn{2}{|l|}{$10-14$ years } & & & & \\
\hline & $\begin{array}{l}\text { R egression } \\
\text { slope }\end{array}$ & $\begin{array}{l}\text { Change per } \\
\text { year }(\%)\end{array}$ & $\begin{array}{l}\text { R egression } \\
\text { slope }\end{array}$ & $\begin{array}{l}\text { Change per } \\
\text { year }(\%)\end{array}$ & $\begin{array}{l}\text { R egression } \\
\text { slope }\end{array}$ & $\begin{array}{l}\text { Change per } \\
\text { year }(\%)\end{array}$ & $\begin{array}{l}\text { R egression } \\
\text { slope }\end{array}$ & $\begin{array}{l}\text { Change per } \\
\text { year }(\%)\end{array}$ & $\begin{array}{l}\text { Regression } \\
\text { slope }\end{array}$ & $\begin{array}{l}\text { Change per } \\
\text { year }(\%)\end{array}$ \\
\hline $\begin{array}{l}\text { Finland } \\
\text { E stonia } \\
\text { Lithuania } \\
\text { L atvia }\end{array}$ & $\begin{array}{l}1.31^{\mathrm{a}} \\
0.45 \\
-0.02 \\
-0.05\end{array}$ & $\begin{aligned} & 5.56^{\mathrm{a}} \\
& 8.34 \\
&-0.93 \\
&-2.78\end{aligned}$ & $\begin{array}{r}-0.24 \\
-0.45 \\
0.08 \\
0.05\end{array}$ & $\begin{array}{r}-0.57 \\
-4.79 \\
1.17 \\
0.96\end{array}$ & $\begin{array}{r}-0.19 \\
-0.05 \\
0.23 \\
-0.03\end{array}$ & $\begin{array}{r}-0.50 \\
-0.42 \\
2.31 \\
-0.24\end{array}$ & $\begin{array}{r}0.16 \\
-0.32 \\
0.13 \\
0.08\end{array}$ & $\begin{array}{r}0.48 \\
-2.84 \\
2.27 \\
1.78\end{array}$ & $\begin{array}{r}0.49 \\
0.29 \\
0.05 \\
-0.13\end{array}$ & $\begin{array}{r}1.54 \\
2.85 \\
0.72 \\
-1.83\end{array}$ \\
\hline
\end{tabular}

${ }^{a} p<0.01$

Novosibirsk, R ussia. Therefore, the observed difference in ID D M risk in R ussians might be due to higher prevalence or intensity of some environmental causal agents in E stonia [32].

Population-based case-control studies have shown an association between a short duration of breast-feeding, early introduction of cow's milk, and an increased risk of IDDM [33-35]. A Ithough the frequency and duration of breast feeding has increased in Finland [35] during the last decade, IDDM incidence has increased significantly in children aged 4 years or under. In comparison, the duration of breast feeding in the Baltic republics, which have markedly lower IDDM incidence, has been and still is very short. In Lithuania [13] less than $30 \%$ of children are breast-fed until the age of 2 months, and cow's milk is introduced very early in life. In E stonia only $21 \%$ of infants were breastfed for more than 3 months in 1994 (T. Podar, personal communication). It is very likely that the duration of breast feeding in Latvia is similar to that of Lithuania and E stonia. From the epidemiological and immunological point of view it seems that the duration of breast feeding and early introduction of cow's milk do not explain the difference in IDDM incidence between countries around the $B$ altic Sea.

During the 10-year period studied IDDM incidence significantly increased only in Finland in the $0-4$ year age group. It has been proposed, that about $25 \%$ of ID D M cases could be explained by existence of two specific high-risk HLA haplotypes [36]. A Ithough Finland and $E$ stonia are ethnically quite similar, the incidence of IDDM in E stonia is closer to the level seen in Lithuania and Latvia than that in Finland. In order to explain the existing differences in incidence by genetic means H LA genotyping of multiplex diabetic families (with an ID D M child diagnosed under 15 years of age) from Finland and $E$ stonia has been performed. No E stonian diabetic patient possessed the A 2,C 1,B 56,D R 4,D Q 8 haplotype which is the third most common transmitted "diabetic" haplotype in Finland with the highest absolute risk of IDDM [37]. Most probably, Finns and Estonians have quite different genetic susceptibility for ID D M .
Whether the higher incidence in $E$ stonians than in $\mathrm{R}$ ussians is somehow related to their genetic similarity with the Finns needs to be addressed in comparative genetic studies.

A lthough a period of 10 years is obviously too short to describe time trends in ID D M incidence adequately the results show that large difference in incidence between Finland and the Baltic republics has not markedly changed during the last decade. $M$ ajor political and economical changes in the Baltic republics have since 1990 influenced lifestyles and environment which may induce changes in IDDM incidence trends. Therefore, longer periods are needed to draw conclusions about variability of IDDM incidence in time in countries around the B altic Sea.

A cknowledgements. This study was partly supported by the grants from Finnish A cademy, National Institutes of Health (D K -37957) and the Novo-N ordisk Foundation. We are grateful for the collaboration of the doctors and nurses treating the diabetic children in our countries.

\section{References}

1. R ewers M, LaPorte RE, King H, Tuomilehto J (1988) Trends in the prevalence and incidence of diabetes: insulin-dependent diabetes mellitus in childhood. World Health Stat Q 41: 179-189

2. Karvonen M , Tuomilehto J, Libman I, LaPorte R (1993) A review of the recent epidemiological data on the worldwide incidence of type 1 (insulin-dependent) diabetes mellitus. World Health Organization DIAMOND Project Group. D iabetologia 36: 883-892

3. B ertrams J, B aur M P (1984) Insulin-dependent diabetes mellitus. In: A lbert ED, Baur M P, Mayr WR (eds) Histocompatibility testing. Springer Verlag, Berlin Heidelberg N ew Y ork, pp 348-358

4. Tuomilehto-Wolf E , Tuomilehto J, Cepaitis Z, L ounamaa R (1989) N ew susceptibility haplotype for type 1 diabetes. DIME Study G roup. Lancet 2: 299-302

5. Borch-J ohnsen K, Joner G, M andrup-Poulsen $T$, et al. (1984) Relation between breast-feeding and incidence rates of insulin-dependent diabetes mellitus. A hypothesis. L ancet 2: 1083-1086

6. Toniolo A , C onaldi PG, G arzelli C, et al. (1985) R ole of antecedent mumps and reovirus infections on the development of type 1 (insulin-dependent) diabetes. E ur J E pidemiol 1: 172-179 
7. D ahlquist $G G$, B lom L G, Persson LA, Sandstrom A I, Wall SG (1990) D ietary factors and the risk of developing insulin dependent diabetes in childhood. B MJ 300: 1302-1306

8. Tuomilehto J, Podar T, R eunanen A, et al. (1991) Comparison of incidence of IDDM in childhood between $E$ stonia and Finland, 1980-1988. D iabetes Care 14: 982-988

9. Tuomilehto J, Podar T, B rigis G, et al. (1992) Comparison of the incidence of insulin-dependent diabetes mellitus in childhood among five Baltic populations during 19831988. Int J Epidemiol 21: 518-527

10. Nevanlinna HR (1972) The Finnish population structure and rare recessive diseases. D uodecim 88: 4-14

11. Podar T, Tuomilehto-Wolf E, Tuomilehto J, LaPorte RE, A dojaan B (1992) Insulin-dependent diabetes mellitus in native $E$ stonians and immigrants to Estonia. A m J E pidemiol 135: 1231-1236

12. A nonymous (1994) State Committee for Statistics of the R epublic of L atvia. R iga

13. Grabauskas V (ed) (1993) L ithuania M C M X C. Health and it's problems. National Conference on health policy. M ED ICINA, Kaunas

14. Tuomilehto J, Lounamaa R, Tuomilehto-Wolf $E$, et al. (1992) E pidemiology of childhood diabetes mellitus in Finland-background of a nationwide study of type 1 (insulindependent) diabetes mellitus. The Childhood Diabetes in Finland (D iM e) Study G roup. D iabetologia 35: 70-76

15. G rabauskas V, U rbonaite B, Padaiga Z (1991) I ncidence of childhood insulin-dependent diabetes mellitus in L ithuania 1983-1988. A cta Paediatr Scand 80: 718-719

16. WH O Diamond Project G roup (1990) W H O Multinational Project for Childhood D iabetes. Diabetes Care 13: 10621068

17. L aPorte RE , M cCarty D, Tull E , Libman I, M atsushima M (1994) Beyond insulin-dependent diabetes mellitus registries: capture-recapture approaches for monitoring incidence. In: D orman JS (ed) Standardization of epidemiologic studies of host susceptibility, vol 270. Plenum Press, New York, L ondon, pp 7-12

18. Diabetes E pidemiology Research International Group (1988) Geographic patterns of childhood insulin-dependent diabetes mellitus. D iabetes 37: 1113-1119

19. D iabetes E pidemiology R esearch International M ortality Study Group (1991) Major cross-country differences in risk of dying for people with IDDM. Diabetes Care 14: 49-54

20. H awthorne G, Snodgrass A, Tunbridge M (1994) O utcome of diabetic pregnancy and glucose intolerance in pregnancy: an audit of fetal loss in N ewcastle G eneral H ospital 1977-1990. D iabetes R es Clin Pract 25: 183-190

21. Sachon C, Grimaldi A, Bosquet F, et al. (1994) D iabetic pregnancy. E valuation and prospects from the study of 212 diabetic pregnancies followed-up between 1985 and 1992. A nn M ed Interne 145: 391-397

22. Warram HJ, K rolewski A S, K ahn CR (1988) D eterminants of IDDM and perinatal mortality in children of diabetic mothers. D iabetes 37: 1328-1334
23. Persson B , H anson U (1993) Insulin dependent diabetes in pregnancy: impact of maternal blood glucose control on the offspring. J Paed Child H ealth 29: 20-23

24. H anson U, Persson B (1993) O utcome of pregnancies complicated by type 1 insulin-dependent diabetes in Sweden: acute pregnancy complications, neonatal mortality and morbidity. A m J Perinatol 10: 330-333

25. Freinkel N, Dooley SL, M etzger BE (1985) Care of the pregnant woman with insulin-dependent diabetes mellitus. New Engl J Med 313: 96-101

26. O mori Y, M inei S, Testuo T, Nemoto K, Shimizu M, Sanaka $M$ (1994) C urrent status of pregnancy in diabetic women. A comparison of pregnancy in IDDM and NIDDM mothers. D iabetes R es Clin Pract 24[Suppl]:S273-S278

27. M albe R, K rievkalna R, G aizauskiene A (1994) $H$ ealth in the Baltic Countries, 1994. Paulauskas polygraphies, Vilnius

28. National A gency for Welfare and Health (1992) Statistics on births in Finland 1990, SV T, vol 6, Helsinki

29. Erkkola R (1994) Maternal mortality in Finland 1970-89. A nn Chir G ynaecol 208[Suppl]:72-75

30. Padaiga $Z$, Marciulionyte $D$, Dobrovolskiene $R$, et al. (1995) Clinical trial "Home blood glucose monitoring" in Lithuanian diabetic children - towards better glycemic control. A cta Med Lit 4: 71-76

31.C rofford OB (1995) The effect of intensive diabetes management on the complications of insulin-dependent diabetes mellitus: R esults of the Diabetes Control and Complications. Trial. In: Cowett RM (ed) D iabetes, vol 35, Nestle Nutrition Workshop Series. Raven press, New York, pp 199-210

32. Podar T, Laporte RE, Tuomilehto J, Shubnikov E (1993) $R$ isk of childhood type 1 diabetes for R ussians in Estonia and Siberia. Int J E pidemiol 22: 262-267

33. V irtanen SM, R asanen L, A ro A, et al. (1992) Feeding in infancy and the risk of type 1 diabetes mellitus in Finnish children. The 'Childhood Diabetes in Finland' Study Group. D iabet Med 9: 815-819

34. V irtanen SM, R asanen $L$, A ro A, et al. (1991) Infant feeding in Finnish children less than $7 \mathrm{yr}$ of age with newly diagnosed IDDM. Childhood Diabetes in Finland Study G roup. D iabetes Care 14: 415-417

35. V irtanen SM, R asanen L, Y Ionen K, et al. (1993) E arly introduction of dairy products associated with increased risk of IDDM in Finnish children. The Childhood in Diabetes in Finland Study G roup. D iabetes 42: 1786-1790

36. Tuomilehto-Wolf E, Tuomilehto J and the DIME Study Group (1993) Is the high incidence of diabetes in young children diagnosed under the age of 4 years determined by genetic factors in Finland? D iabete M etab 19: 167-172

37. Tuomilehto-Wolf E, Podar T, A dojaan B, Kalits I, Tuomilehto J (1991) Can the difference in incidence of type 1 diabetes between $\mathrm{E}$ stonia and Finland be partly explained by genetic reasons? Diabetologia 34[Suppl.2]:A 65(A bstract) 